\title{
Recurrent vomiting in a toddler; oesophageal food bolus impaction
}

\author{
Sinhabahu VP $P^{1}$, Jamison $S^{2}$, Cunninghams $S^{2}$ \\ 'Kalawana Base Hospital, Kalawana, Sri Lanka. \\ ${ }^{2}$ Children's Emergency Department, Starship Children's Health, Auckland, New Zealand.
}

Correspondence: Dr. Vindika Prasad Sinhabahu

e-mail:sinbad.lk@gmail.com

D https://orcid.org/0000-0003-0065-2845

Submitted on 22.07.2020 and accepted for publication on 27.12.2020

\section{Introduction}

Vomiting is common in children. Vomiting or emesis, is the actual oral expulsion of gastrointestinal contents as a result of contractions of the gastrointestinal and the thoracoabdominal wall musculature (1). Vomiting centre in medulla oblongata comprises of reticular formation and the nucleus of the tractus solitarius. Motor pathways descend from vomiting centre trigger vomiting when stimulated. These efferent pathways travel within the $5^{\text {th }}, 7^{\text {th }}, 9^{\text {th }}, 10^{\text {th }}$, and $12^{\text {th }}$ cranial nerves to the upper gastrointestinal tract, within vagal and sympathetic nerves to the lower tract, and within spinal nerves to the diaphragm and abdominal muscles. The vomiting centre can be activated directly by irritants or indirectly following input from four principal areas: gastrointestinal tract, cerebral cortex and thalamus, vestibular region, and chemoreceptor trigger zone (CRTZ) (1). Local causes such as gastrointestinal infection or obstruction, pharyngitis and systemic causes such as sepsis, increased intracranial pressure and chemotherapy can give rise to repeated episodes of vomiting by triggering the vomiting centre. Oesophageal food bolus is a rare cause of vomiting in children (2). One study had estimated that the incidence of upper gastrointestinal food bolus impaction is 13 per 100,000 populations (3). More than $80 \%$ of children with oesophageal food bolus impaction have an abnormality in the oesophagus (2). We describe a case of a toddler with recurrent vomiting due to oesophageal food bolus impaction.

\section{Case presentation}

A previously healthy twelve-month-old boy with sudden onset of recurrent vomiting was transferred from a regional hospital for surgical evaluation of possible intussusception. He has had cough and coryzal symptoms for four days prior to the presentation. He had a normal bowel motion on the day of admission prior to attending day care. On the day of admission, he had attended to his regular day care centre and had developed nonbilious vomiting during his stay there.

He has had all immunisations for the age according to New Zealand immunisation schedule. He had achieved developmental milestones at appropriate age. On examination at the regional hospital, his temperature was $36.9{ }^{\circ} \mathrm{C}$, he was drowsy and lethargic. His pulse rate was 132 beats/min, respiratory rate was 24 breaths/min and oxygen saturation was $99 \%$ on air. His Abdomen was soft, non-tender with normal bowel sounds. A sausage shaped mass was felt in central abdomen. Rest of the examination was normal. Chest and abdominal radiographs and urine analysis were normal. He was started on $0.9 \%$ saline $+5 \%$ dextrose maintenance fluid and transferred to Starship Children's Health, Auckland for surgical opinion on suspicion of intussusception.

On arrival, his temperature was $36.5{ }^{\circ} \mathrm{C}$, pulse rate was 130 beats/min, respiratory rate was 26 breaths/ min and Oxygen saturation on air was $97 \%$. 
He continued to vomit despite intravenous ondansetron $100 \mu \mathrm{g} / \mathrm{kg}$ and also required and $20 \mathrm{ml} / \mathrm{Kg}$ of $0.9 \%$ saline. An ultrasound scan (USS) of the abdomen did not show any evidence of intussusception. He remained pale and floppy with intermittent vomiting 10 hours after the onset of his symptoms. CT scan of the brain was done to exclude an intracranial pathology such as space occupying lesion as a cause for vomiting. It was normal. He had full septic screen including urine analysis and culture, full blood count, C-reactive protein, blood culture and cerebrospinal fluid analysis with culture to exclude sepsis as the cause for lethargy and vomiting. Septic screen was normal. Intravenous amoxicillin $50 \mathrm{~g} / \mathrm{kg} 6$ hourly and cefotaxime $50 \mathrm{mg} / \mathrm{kg} 6$ hourly were started empirically while awaiting septic screen results.

Sixteen hours after the onset of vomiting, he developed mild stridor with difficulty in breathing and oxygen desaturation to $84 \%$ in room air. Air entry was equal on auscultation of his chest. His oxygen saturation corrected with oxygen $10 \mathrm{~L} / \mathrm{min}$ via a face mask.

Lateral neck radiograph showed compression of trachea with a possible food bolus in oesophagus (Figure 1).

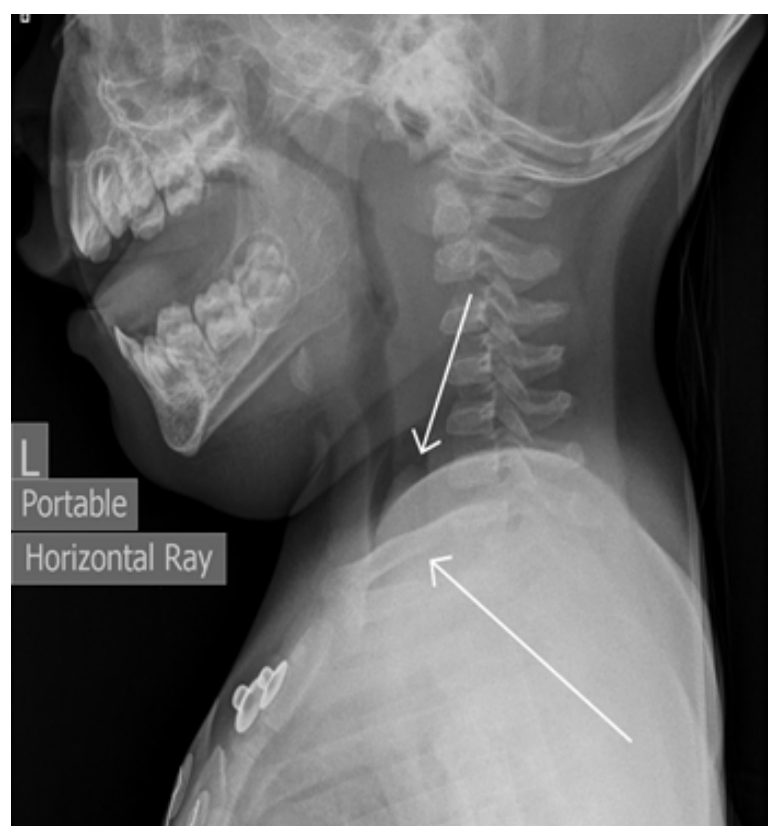

Figure 1: Lateral neck X-ray showing a food bolus (marked in arrows) in oesophagus with compression of trachea
An oesophagoscopy under general anaesthesia revealed a dried apricot lodged in the oesophagus. The apricot was difficult to extract as it was swollen and the surrounding tissue was oedematous. It was dislodged and pushed into the stomach. Rest of the oesophagus was normal. The child had an uneventful recovery.

A history of a choking or gagging incident could not be obtained retrospectively. On further inquiry it was revealed that the child had dried apricots for lunch at day care centre.

\section{Discussion}

Recurrent vomiting and lethargy with concurrent illness in a toddler has wide differential diagnoses. Intussusception was considered as there was an abdominal mass with vomiting. Target lesion appearance in USS of abdomen is seen in $98 \%$ of children with confirmed intussusception (4). Intussusception is unlikely in a child with a normal abdominal ultrasound examination. Our child had a normal ultrasound scan of abdomen which made intussusception unlikely. The presence of concurrent illness was noted in $30 \%$ at presentation of intussusception (5).

Oesophageal foreign bodies are a cause of stridor and difficulty in breathing (3). The dried apricot became larger in the oesophagus with time as swollen with saliva causing tracheal compression leading to stridor and desaturations.

Factors that determine food impaction include the state of the oesophagus and the nature of the food that has been swallowed (6). Food bolus impactions have underlying oesophageal pathology in $88 \%$ to $97 \%$ of adult patients evaluated (6). Coins are the commonest ingested foreign body in children worldwide (7). A study in a single centre in Sri Lanka showed that peak age of foreign body ingestion in children ranged from 1 - 5 years (8). Most common ingested foreign bodies were button batteries $(24 \%)$ and coins $(17 \%)$ and upper gastrointestinal endoscopy was needed in $22 \%$ of children to remove foreign body (8). An abnormality of the oesophagus such as eosinophilic oesophagitis or narrowing at the site of prior oesophageal or oesophageal-related surgery was found in more than $80 \%$ of paediatric 
patients with oesophageal food bolus impaction (5). Endoscopy did not reveal any anatomical abnormality in our patient. Biopsies were not done as oesophagus was morphologically normal.

Large dried fruits such as whole apricots which cause oesophageal food bolus in this case, are not safe food for infants and toddlers due to choking hazard. Fruits such as Veralu, dates, and ripe Jack fruit may have a chance of causing food bolus impaction in Sri Lankan Setting. It is important to consider the size of the food given and the ability of the child to chew to minimise the risk of food bolus impaction. At the same time, close supervision of children during meal time can minimize such hazards.

\section{Acknowledgements}

We would like to thank Department of Radiology and Department of Surgery in Starship Children's Health for the support in managing our patient.

\section{References}

1. Becker DE. Nausea, vomiting, and hiccups: A review of mechanisms and treatment. Anesth Prog. 2010; 57(4): 150157. DOI: 10.2344/0003-3006-57.4.150.

2. Liew Z, McKean MC, Townshend J, et al. Oesophageal foreign body presenting with stridor associated with feeding. Archives of Disease in Childhood. 2013; 98: 384385. Available from: https://adc.bmj.com/content/98/5/ 384.long (Accessed on 2018.07.14).

3. Vizcarrondo FJ, Brady PG, Nord HJ. Foreign bodies of the upper gastrointestinal tract. Gastrointest Endosc. 1983 Aug; 29(3): 208-210. DOI: 10.1016/s0016-5107(83) 72586-1.
4. Lai AH, Phua KB, Teo EL, Jacobsen AS Intussusception: A three-year review. Annals of Academy of Medicine Singapore. 2002 Jan; 31(1): 81-5. Available from: https://www.ncbi.nlm.nih.gov/pubmed/11885503. (Accessed on 13.12.2017).

5. Lochhead A, Jamjoom R, Ratnapalan S. Intussusception in children presenting to the emergency department. Clinical Pediatrics. 2013 Nov; 52(11): 1029-33. Available from: https://www.ncbi.nlm.nih.gov/pubmed/24137037 (Accessed on 2017.12.13)

6. Ko HH, Enns R. Review of food bolus management. Can J Gastroenterol. 2008; 22(10): 805-808. DOI: $10.1155 / 2008 / 682082$.

7. Jayachandra S, Eslick GD A systematic review of paediatric foreign body ingestion: presentation, complications, and management. International Journal of Pediatric Otorhinolaryngology. 2013 Mar; 77(3): 311-7. Available from: https://www.ncbi.nlm.nih.gov/ pubmed/23261258 (Accessed on 16.12.2017).

8. Branavan B, Dias R, Kumari T, Samarasinghe M. Foreign body ingestion in children: Single institutional experience in Sri Lanka. Sri Lanka Journal of Child Health. 2014; 43(2), 88-91. DOI: 10.4038/sljch. v43i2.7009.

9. Diniz LO, Towbin AJ. Causes of esophageal food bolus impaction in the paediatric population. Dig Dis Sci. 2012 Mar; 57(3): 690-693. DOI: 10.1007/s10620-011-1911-8. 